\title{
ORGANIZAÇÃo FINANCEIRA NA CONVERSÃO DE ÁREA AO SISTEMA PLANTIO DIRETO
}

\author{
Douglas Vianna Bahiense ${ }^{1}$ \\ Maria da Penha Angeletti ${ }^{2}$ \\ Evelson Sanche Muniz ${ }^{3}$ \\ Jacimar Luis de Souza ${ }^{4}$ \\ Lucinéia Laurett $^{5}$ \\ Rogério Carvalho Guarçoni ${ }^{6}$
}

Resumo: Objetiva-se nesse trabalho a organização financeira de indicadores técnicos obtidos em uma área em conversão ao Sistema de Plantio Direto - SPD ou SPDP, no Sitio Sanche, Santa Maria de Jetibá, Estado do Espírito Santo. Á área em conversão está no sexto ano de aplicação dos três princípios do SPDP, em 0,49 hectares, cultivado com hortaliças e grãos. Neste trabalho foram utilizados três tipos de organização financeira: Custo de produção, Receita Bruta e Fluxo de Caixa Simples. A análise financeira indicou que o Sistema de Plantio Direto tende a crescer economicamente a partir do segundo ano, com o incremento da produção das culturas e com a redução da utilização de insumos e de mão-de-obra. Isto permite inferir que novos projetos de pesquisa e desenvolvimento precisam abordar a rotação de culturas estudando-se espécies econômicas de maior valor agregado, e também o manejo para minimizar os gastos. A educação financeira dos participantes da Rede mostra-se necessária para consolidar este ponto de vista.

Palavras-chave: Tecnologias para a agricultura familiar; Base financeira; Sustentabilidade; Tecnologias em SPD; Produção de hortaliças e grãos em SPD.

\footnotetext{
1 Instituto Capixaba de Pesquisa Assistência Técnica e Extensão Rural - INCAPER/Centro Regional de Desenvolvimento Rural Centro Serrano - Brasil. E-mail: douglas.bahiense@yahoo.com.br.

2 Instituto Capixaba de Pesquisa Assistência Técnica e Extensão Rural - INCAPER/Centro Regional de Desenvolvimento Rural Centro Serrano - Brasil. E-mail: penhangeletti@incaper.es.gov.br.

${ }^{3}$ Sindicato dos Trabalhadores Rurais Agricultores e Agricultoras Familiares de Santa Maria de Jetibá - STRSMJ - Brasil. E-mail: evelsonsanche@bol.com.br.

4 Instituto Capixaba de Pesquisa Assistência Técnica e Extensão Rural - INCAPER/Centro Regional de Desenvolvimento Rural Centro Serrano - Brasil. E-mail: jacimarsouza@yahoo.com.br.

${ }^{5}$ Sindicato dos Trabalhadores Rurais Agricultores e Agricultoras Familiares de Santa Maria de Jetibá - STRSMJ - Brasil. E-mail: laurett24@hotmail.com.

6 Instituto Capixaba de Pesquisa Assistência Técnica e Extensão Rural - INCAPER/Centro Regional de Desenvolvimento Rural Centro Serrano - Brasil. E-mail: rogerio.guarconi@gmail.com.
} 